\title{
Crescimento Ponderal de Filhotes de Tartaruga Gigante da Amazônia (Podocnemis expansa) Submetidos a Tratamento com Rações Isocalóricas contendo Diferentes Níveis de Proteína Bruta
}

\author{
Vinicius Augusto Sá1, Leonardo C. Quintanilha ${ }^{2}$, Gustavo Eduardo Freneau ${ }^{3^{*}}$, Vera Lucia \\ Ferreira Luz ${ }^{4}$, Arcádio de Los Reyes Borja ${ }^{5}$, Paulo César Silva ${ }^{5}$
}

\begin{abstract}
RESUMO - A criação de Podocnemis expansa, a tartaruga-da-amazônia, com finalidade comercial foi implantada no Brasil em 1992. Contudo, muitas questões acerca do manejo, da nutrição, da sanidade e, principalmente, da reprodução ainda são obscuras. Visando contribuir para o desenvolvimento de uma metodologia alimentar da espécie, objetivou-se testar diferentes níveis de proteína da dieta. Uma amostra de 480 animais neonatos de, aproximadamente, um mês de vida foram trazidos de uma área de proteção localizada no rio Araguaia no Estado Goiás para o Núcleo de Pscicultura Experimental/UFG. Os animais foram divididos em seis grupos de 80 animais e colocados em caixas de água de 500 litros. Cinco grupos receberam rações formuladas com diferentes teores de proteína bruta (PB) vegetal: PB 18\% (PB18), PB 21\% (PB21), PB 24\% (PB24), PB 27\% (PB27) e PB 30\% (PB30), enquanto o outro grupo (PBA30) recebeu ração comercial para peixes contendo proteína de origem animal (30\% de PB). Bimestralmente, foram realizadas biometrias para determinação das medidas de comprimento (CC) e largura da carapaça (LC), comprimento da carapaça (CP) e largura do plastrão (LP) e do peso corporal (PC). O experimento demonstrou superioridade do tratamento PBA30 em todas as medidas estudadas, seguidos seqüencialmente pelos tratamentos PB30, PB27, sem diferenças significativas entre estes grupos. Os piores resultados foram para os grupos PB24, PB21 e PB18, que não diferiam entre si. Filhotes de $P$. expansa nos dez primeiros meses de vida alimentados com dietas contendo elevados percentuais de proteína bruta (acima de 27\%) respondem melhor em termos de crescimento e ganho de peso que aqueles alimentados com dietas com percentuais mais baixos. A dieta contendo proteína bruta de origem animal apresentou melhores resultados que as de origem vegetal.
\end{abstract}

Palavras-chave: crescimento, neonatos, nutrição, proteína, quelônios

\section{Body Growth of One-Month Giant Amazonian Turtle (Podocnemis Expansa) Fed Isocaloric Diet with Different Levels of Crude Protein Concentration}

\begin{abstract}
The domestication of Podocnemis expansa (Gigant Amazonian turtle) with commercial purpose it was implanted in Brazil in 1992. However, a lot of subjects about handling, nutrition, sanity and mainly reproduction are still obscure these animals. The objective of this study was evaluated the effects of crude protein concentration and source on body weight of Podocnemis expansa. The turtles ( $\mathrm{n}=480$ ) were transferred to Setor de Piscicultura EV/UFG. Six animal groups (80/each) were put in water tanks of 500 liters. Five groups received rations formulated to different concentration of crude protein (CP) vegetable: CP 18\% (PB18), CP 21\% (PB21), CP 24\% (PB24), CP 27\% (PB27) and CP 30\% (PB30). Another group (PBA30) was fed commercial ration for fish with 30\% of PB of animal source. Body weight (PC), the length measures (CC) and width of the shell (LC), length (CP) and width of the breastplate (LP), were evaluated every 60 days. The body weight was higher for turtles fed PBA30 diet than those fed PB30, PB27 diets, without differences among these groups. The lower biometric measures were observed for groups fed PB24 PB21 and PB18 diets, that did not differ among them. Little turtle of P. expansa in the first ten months of life fed diet with crude protein concentration higher than $27 \%$ showed higher body biometric measures than those fed with diets with lower protein concentration. The diet containing crude protein of animal origin presented better results than the one of vegetable origin.
\end{abstract}

Key Words: growth, protein, neonates, nutrition, turtle

\section{Introdução}

A criação de animais silvestres com finalidade comercial é uma atividade ainda em desenvolvimento no Brasil. Mais que uma nova atividade comercial, arepresenta utilização sustentável dos recursos naturais, promove a valorização dos recursos faunísticos nacionais e, ainda, representa uma fonte

\footnotetext{
${ }^{1}$ Médico Veterinário, Msc Instituto de Ciências Biológica UFG. E.mail: viniciusaugusto@agricultura.gov.br

2 Médico Veterinário, Msc Instituto de Ciências Biológica UNB.

3 Professor Dr. Laboratório de Andrologia e Tecnologia do Sêmen - DPA - Escola de Veterinária - UFG, CP 131, Campus II Goiânia-Go E.mail: gfreneau@vet.ufg.br $\left(^{*}\right)$.

4 IBAMA - RAN Goiânia, Goiás. E.mail: vlucia@go.ibama.gov.br

${ }^{5}$ Professores Dr. Departamento de Produção Animal e Setor de Piscicultura EV-UFG.
} 
de proteína animal altamente adaptada às reais condições naturais do ambiente tropical sul-americano.

Os quelônios amazônicos, em especial a Podocnemis expansa e a Podocnemis unifilis, são espécies com altíssimo potencial para exploração zootécnica, particularmente por seu porte, sua alta prolificidade, rusticidade e pelo alto valor econômico que agrega sua carne e seus subprodutos.

A criação de quelônios em cativeiro no Brasil vem despertando o interesse econômico dos produtores rurais, desde a década de 70, após a publicação da Lei 5.197/67 - Lei de Proteção à Fauna, a qual preconiza a proibição de captura e comercialização de animais silvestres, se não provenientes de criadouros legalizados. Atualmente, $P$. Expansa e $P$ unifilis são espécies liberadas para criação em cativeiro.

Adultos de $P$. expansa na natureza são considerados herbívoros e, em alguns casos, se comportam como onívoros, também ingerindo, em quantidades menores, alimentos de origem animal (Ojasti 1967). Espécimes de $P$. expansa em cativeiro são eminentemente onívoros, aceitando grande variedade de produtos vegetais, de pescados e de carne picada (Alho \& Pádua,1982). Filhotes de P. expansa parecem ter preferência por dietas com maior proporção de produtos de origem animal que os animais maiores (Ojasti,1967).

A maioria dos criadouros alimenta os animais com produtos e subprodutos acessíveis regionalmente, constituídos, principalmente, por grãos, tubérculos, frutos e verduras.

O desenvolvimento da quelonicultura está inerente à obtenção de informações sobre a alimentação satisfatória e índices de reprodução. Atualmente, existem no Brasil 92 criadouros comercias e conservacionistas de tartaruga-da-amazônia, com aproximadamente 880.000 animais, com a entrega comprometida de mais 290.000 até 2004. Deste total de animais, 10\% será destinado à reprodução, em função da Portaria IBAMA 142, de 30 de dezembro de 1992.

Não existem na literatura trabalhos que abordem aspectos nutricionais de animais desta espécie criados em cativeiro. Portanto, este estudo foi desenvolvido com o objetivo de aferir o crescimento de filhotes de $P$. expansa, alimentados com rações contendo diferentes níveis de proteína, a fim de viabilizar o melhor manejo nutricional para fins comerciais.

\section{Material e Métodos}

O experimento foi conduzido no Setor de Pscicultura Experimental da Escola de Veterinária da Universidade Federal de Goiás (UFG), no município de Goiânia - Goiás, que se localiza a uma latitude sul de $16^{\circ} 40^{\prime} 22^{\prime \prime}$ e longitude de $49^{\circ} 15^{\prime} 29^{\prime}$ ' a oeste de Greenwich, com altitude média de $730 \mathrm{~m}$. O clima da região é do tipo B2WB'4a' e apresenta temperaturas médias de $21,9^{\circ} \mathrm{C}$, com máxima de $29,4^{\circ} \mathrm{C}$ e mínima de $15,2^{\circ} \mathrm{C}$, umidade relativa média de $71,5 \%$, precipitação pluviométrica de 1487,2 mm e insolação total de 2645,7h (INMET, 2002). O experimento foi conduzido durante 10 meses, de dezembro de 1996 ao final outubro de 1997.

O CENAQUA/IBAMA forneceu 480 animais neonatos, nascidos nas bases de manejo reprodutivo de covas, filhotes de proteção ambiental, localizadas entre Cocalinho e Bandeirantes, região do médio Araguaia, entre os Estados de Goiás e de Mato Grosso. Os neonatos chegaram ao local do experimento com aproximadamente 15 dias de vida e foram, aleatoriamente, distribuídos em seis grupos com 80 animais cada.

Utilizaram-se seis caixas de amianto de 1,20x0,58x0,85m com capacidade para 500 litros de água, dispostas em duas fileiras paralelas recebendo sistemas de abastecimento e drenagem de água. Tubos de PVC de 200mm foram cortados longitudinalmente para se confeccionar os comedouros. Foram fixados em uma das paredes do tanque, de modo que ficassem a poucos centímetros abaixo da superfície de água. Em cada tanque colocaram-se plataformas com rampas flutuantes para que os animais pudessem assoalhar.

Para compor as rações, selecionou-se um grupo de alimentos comumente utilizados no Estado de Goiás na fabricação de rações para animais domésticos. Os alimentos foram selecionados considerando-se sua homogeneidade de produção durante o ano e preço, bem como algumas características que poderiam ser análogas aos vegetais consumidos por $P$. expansa na natureza. Todas as rações foram formuladas com alimentos de origem vegetal, com exceção da fonte de cálcio. Os alimentos selecionados para compor as rações foram: farelo de soja; farelo de trigo; milho em grão triturado; farelo de algodão; farelo de arroz; farinha de ostras; fosfato bicálcico; premix e sal comum. Os farelos de soja, de trigo, de 
arroz e de algodão e o milho triturado foram submetidos a análises centesimais, realizadas no Laboratório de Nutrição Animal/UFG. A finalidade destas análises foi conhecer melhor o valor nutricional dos ingredientes, de forma a proporcionar valores reais quando da formulação das rações. Realizaram-se as análises bromatológicas dos ingredientes, para determinação da matéria seca - MS, a pré-secagem a $65^{\circ} \mathrm{C}$ e a secagem a $105^{\circ} \mathrm{C}$ da proteína bruta - PB (micro Kjedahl), do extrato etéreo - EE (Soxhlet), da fibra bruta - FB $\left(\mathrm{H}_{2} \mathrm{SO}_{4} 1,25 \% / \mathrm{NaOH} 1,25 \%\right)$, da matéria mineral - MM (calcinação a $600^{\circ} \mathrm{C}$ ), do extrato nãonitrogenado - ENN e da energia bruta - EB, a partir de modelos matemáticos, segundo metodologia descrita por Silva (1990).

Cinco grupos receberam rações formuladas com diferentes teores de proteína bruta (PB) vegetal com base nos resultados centesimais: PB 18\% (PB18), PB 21\% (PB21), PB 24\% (PB24), PB $27 \%$ (PB27) e PB 30\% (PB30). Para o grupo controle, administrou-se uma ração comercial para peixe com 30\% PB (PBA30) proteína de origem animal em sua formulação, obtendo-se, assim, um total de seis tratamentos (Tabela 1), alocando-se um tratamento por tanque com 80 animais. As repetições de colheita de dados foram determinadas ao longo do tempo (idades dos animais).

As rações foram formuladas adotando-se o modelo matemático de Pearson. Em decorrência de interações nutricionais entre a fibra bruta, a energia e a proteína bruta, procurou-se formular cinco rações de modo que possuíssem níveis de fibra bruta e de energia semelhantes, variando somente os níveis de proteína bruta. As rações foram peletizadas $(12 \times 5 \mathrm{~mm})$ e fornecidas à vontade aos animais. Os alimentos eram fornecidos diariamente, uma vez ao dia, pela manhã. Procurando diminuir a influência do posicionamento do tanque, semanalmente, após a lavagem destes, os grupos de animais eram rotacionados, passando de uma caixa para outra.

Com auxílio de paquímetro e de balança, efetuaram-se medições de biometria $(\mathrm{cm})$ e de peso corporal (gramas) regularmente de todos os animais a cada 60 dias, totalizando seis colheitas de dados no período de janeiro a novembro de 1997. Os parâmetros registrados nas biometrias foram: comprimento da carapaça (CC), largura da carapaça (LC), comprimento do plastrão (CP), largura do plastrão (LP) e peso corporal (PC). O CC corresponde à medida entre os primeiros escudos marginais dorsais (ou nucais) até a sutura dos últimos escudos marginais dorsais (ou supracaudais). A LP corresponde à medida da distância dorsal entre o $6^{\circ}$ e $7^{\circ}$ escudos marginais entre ambos os lados. O CP corresponde à medida dorsal que vai da borda anterior do escudo intergular até o ponto posterior da sutura dos escudos anais. A LP corresponde à distância ventral mais lateral entre os pontos de inserção dos escudos abdominais e peitorais com os escudos marginais direito e esquerdo. Para as medidas, foi utilizado um paquímetro metálico de precisão $0,05 \mathrm{~mm}$. As medidas foram efetuadas considerando-se duas casas decimais. Para pesagem, utilizou-se uma balança eletrônica com precisão de um grama.

Foi utilizado o Índice Agregativo Simples (Martins \& Donaire,1995), para análise e elaboração de índices sintéticos relativos de base móvel, para se verificar as mudanças ocorridas ao longo do tratamento. Os índices agregativos simples foram obtidos para: comprimentos da carapaça e do plastrão (ICC; ICP); larguras da carapaça e do plastrão (ILC; ILP); e peso corporal (IPC). O índice global agregou os valores médios de todas as variáveis aferidas e foi denominado índice de crescimento ponderal (ICRP). Os dados brutos foram submetidos à análise de comparações múltiplas,

Tabela 1 - Dados do valor nutricional das rações oferecidas a tartarugas gigantes da Amazônia até os 10 meses de idade

Table 1 - Data of the nutritional value of the rations offered to gigant Amazonian turtles until 10 months of age

\begin{tabular}{lccc}
\hline $\begin{array}{l}\text { Tratamento } \\
\text { Treatment }\end{array}$ & $\begin{array}{c}\text { Proteína bruta } \\
\text { Crude protein }\end{array}$ & $\begin{array}{c}\text { Energia bruta }(\mathrm{kcal} / 100 \mathrm{~g}) \\
\text { Crude energy }\end{array}$ & $\begin{array}{c}\text { Fibra bruta (FB) } \\
\text { Crude fiber }\end{array}$ \\
\hline PBA30 & $30 \%$ & 39,95 & $5,5 \%$ \\
PB18 & $18 \%$ & 39,55 & $7,09 \%$ \\
PB21 & $21 \%$ & 39,66 & $7,13 \%$ \\
PB24 & $24 \%$ & 39,76 & $7,16 \%$ \\
PB27 & $27 \%$, & 39,87 & $7,20 \%$ \\
PB30 & $30 \%$ & 39,97 & $7,24 \%$ \\
\hline
\end{tabular}

R. Bras. Zootec., v.33, n.6, p.2351-2358, 2004 (Supl. 3) 
com médias ajustadas para o método de Tukey Kramer, e à análise de regressão, pelo procedimento GLM (SAS, 1997).

\section{Resultados e Discussão}

Em animais com crescimento contínuo, sobretudo nas fases iniciais de crescimento, o tamanho corporal está relacionado à idade e ao tipo de alimentação, podendo, em muitos casos, a taxa de crescimento ser definida pela relação com a idade do animal (Bataus, 1998).

Ao final de dez meses de observações e, segundo a análise de regressão e o teste Tukey, obtiveram-se os resultados das características de crescimento corporal, em função da idade, representadas por equações que delinearam curvas com fases iniciais de crescimento lento e, posteriormente, nas idades mais avançadas, apresentaram aceleração da curva.

O peso corporal (Figura 1) foi superior no grupo PBA30 (filhotes que receberam ração comercial com proteína animal), seguido pelos grupos que receberam rações elaboradas com proteína vegetal e níveis de 27 e 30\% (PB27, PB30), respectivamente, sendo que estes últimos não diferiram entre si. Os tratamentos PB24, PB21 e PB18 tiveram os resultados mais baixos ao final do experimento e não diferiram estatisticadmente entre si (Tabela 2).

Houve relação entre o peso corporal e a idade dos animais $(\mathrm{p}<0,0001)$ representados por uma curva $\left(\mathrm{R}^{2}=0,82\right)$ para cada tratamento:

PBA30 $=29,627-0,109 x+0,0014 x^{2} ;$ PB18 $=29,627-$ $0,068 \mathrm{x}+0,0009 \mathrm{x}^{2}$;

PB21=29,627-0,020 $x+0,0007 x^{2} ;$ PB24=29,627$0,011 \mathrm{x}+0,008 \mathrm{x}^{2}$;

PB27 $=29,627-0,043 x+0,001 x^{2} ; \quad$ PB30 $=29,627-$ $0,023 \mathrm{x}+0,0009 \mathrm{x}^{2}$.

Esta relação apresentou maior taxa de crescimento no grupo PBA30, em que sua curva se distanciou das demais curvas dos outros tratamentos (Figura 1).

O comprimento da carapaça (Figura 2) foi superior no grupo PBA30, seguido pelos grupos que tiveram ração elaborada para o tratamento PB30, PB27, PB24, que não diferiram entre si. Os grupos PB21 e PB18 tiveram os piores resultados ao fim do experimento (Tabela 2).

Houve relação entre o comprimento da carapaça e a idade dos animais $(\mathrm{p}<0,0001)$, representados por equações no modelo $\left(\mathrm{R}^{2}=0,86\right)$ para cada tratamento:

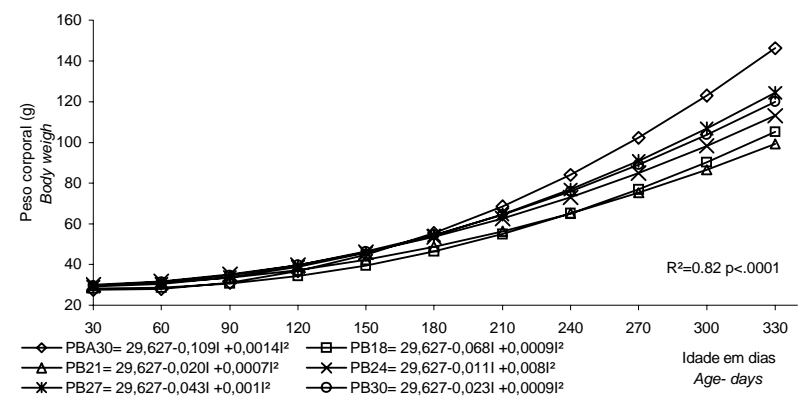

Figura 1 - Peso corporal de filhotes de tartarugas gigantes da Amazônia (P.expansa) alimentados com dietas de diferentes níveis de proteína bruta.

Figure 1 - Body weight of nestlings Gigant Amazoniam turtle (P.expansa) fed diets with different crude protein levels.

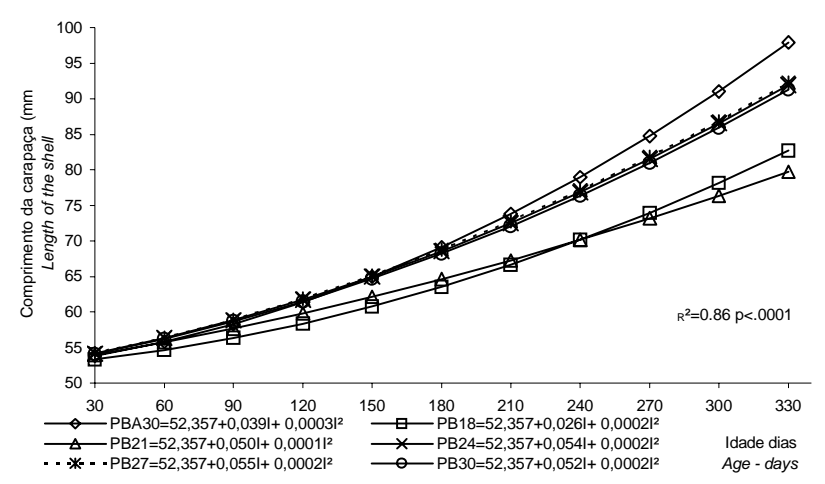

Figura 2 - Incremento de comprimento da carapaça de filhotes de tartarugas gigantes da Amazônia ( $P$. expansa) alimentados com dietas de diferentes níveis de proteína bruta.

Figure 2 - Increase of length of the shell of nestlings Gigant Amazoniam turtle (P.expansa) fed diets with different crude protein levels.

$$
\begin{aligned}
& \text { PBA30 }=52,357+0,039 x+0,0003 x^{2} \\
& \text { PB18 }=52,357+0,026 x+0,0002 x^{2} ; \\
& \text { PB21 }=52,357+0,050 x+0,0001 x^{2} ; \\
& \text { PB24 }=52,357+0,054 x+0,0002 x^{2} ; \\
& \text { PB27 }=52,36+0,055 x+0,0002 x^{2} ; \\
& \text { PB30 }=52,357+0,052 x+0,0002 x^{2}
\end{aligned}
$$

As curvas observadas no modelo para a relação da idade com o comprimento da carapaça apresentaram três grupos diferenciados de crescimento (PBA30; PB30, PB24 e PB27; PB21 e PB18), constatação não observada no comportamento da relação do peso corporal com a idade dos animais (Figuras 1 e 2). 
A largura da carapaça o tratamento PBA30 foi superior (Figura: 3), seguido dos grupos PB24, PB30 e PB27. Os tratamentos PB21 e PB18, respectivamente, apresentaram os piores resultados em relação aos outros tratamentos (Tabela 2).

Houve relação entre a largura da carapaça e a idade dos animais $(\mathrm{p}<0,0001)$, representada por equações no modelo $\left(\mathrm{R}^{2}=0,84\right)$ para cada tratamento (Figura 3):

PBA30 $=48,639+0,024 x+0,0002 x^{2} ;$ PB18 $=$ $48,639+0,023 \mathrm{x}+0,0001 \mathrm{x}^{2}$;

PB21 $=48,639+0,040 \mathrm{x}+0,0001 \mathrm{x}^{2} ;$ PB24 $=$ $48,639+0,045 x+0,0001 x^{2}$;

PB27 $=48,639+0,039 x+0,0001 x^{2} ;$ PB30 $=$ $48,639+0,040 x+0,0001 x^{2}$.

Nesta característica, as curvas se apresentaram mais dispersas, destacando-se como maiores $(\mathrm{P}<0,05)$ os tratamentos PB30, PB27 e PB24 como um comportamento ou tendência mais homogênea. O grupo PBA30 da mesma forma que as características anteriores teve sua curva mais elevada (Figura 3 ).

A largura plastrão (Figura 4), aos 330 dias do experimento, foi superior no grupo PBA30. Os grupos que receberam ração com teor de proteína vegetal de PB30, PB27, PB24 PB21, PB18, respectivamente, apresentaram diferenças entre si, porém com valores próximos (Tabela 2).

Houve relação entre a largura do plastrão e a idade dos animais $(\mathrm{p}<0,0001)$, representados por equações no modelo $\left(\mathrm{R}^{2}=0,85\right)$ para cada tratamento:

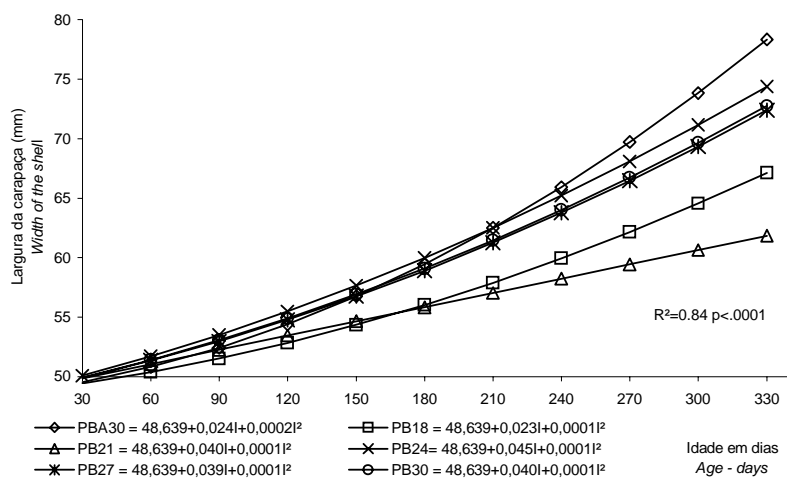

Figura 3 - Incremento de largura da carapaça de filhotes de tartaruga gigantes da Amazônia ( $P$. expansa) alimentados com dietas de diferentes níveis de proteína bruta.

Figure 3 - Increase of width of the shell of nestlings Gigant Amazoniam turtle (P.expansa) fed diets with different crude protein levels.

R. Bras. Zootec., v.33, n.6, p.2351-2358, 2004 (Supl. 3)
PBA30 $=46,518-0,002 x+0,0004 x^{2} ;$ PB18 $=46,518-$ $0,004 x+0,0002 x^{2}$;

PB21 $=46,518-0,011 x+0,0002 x^{2} ;$ PB24 = 46,518$0,018 x+0,0002 x^{2}$;

PB27 $=46,518-0,010 x+0,0002 x^{2} ;$ PB30 = 46,518$0,0122 \mathrm{x}+0,0002 \mathrm{x}^{2}$

Esta característica apresentou maior distância entre a curva do tratamento PBA30 com as demais curvas (PB30, PB27, PB24, PB21 e PB18), sendo a primeira mais elevada (Figura 4), demonstrando o maior crescimento dos animais submetidos a dietas com proteína animal.

Na Tabela 2, encontram-se as médias das características de crescimento corporal aferidas no período experimental. A partir dos 210 dias de idade, começaram a ocorrer diferenças entre os tratamentos, que, com o avanço da idade, ficaram mais evidentes. Ogrupo dos animais alimentados com dietas compostas de proteína animal (PBA30) apresentou os maiores $(\mathrm{P}<0,05)$ valores de crescimento. Este grupo foi seguido pelos tratamentos com 30 e 27\% de PB (PB30 e PB27). Na maior parte das comparações, os grupos de animais PB18 e PB21 manifestaram os piores desempenhos de crescimentos em todas as características aferidas. Estas constatações se confirmam com as relações observadas entre as características de crescimento corporal com a idade dos animais (Figuras 1 a 4), em que as curvas de regressão demonstraram um afastamento do grupo PBA30 dos demais grupos, com estádios intermediários para os grupos PB30 e

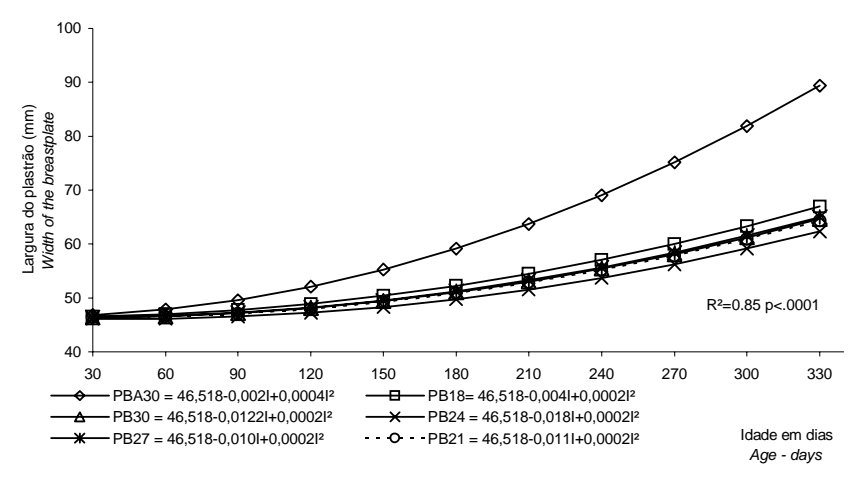

Figura 4 - Incremento da largura do plastrão de filhotes de tartarugas gigantes da Amazônia (P.expansa) alimentados com dietas de diferentes níveis de proteína bruta.

Figure 4 - Increase of width of the breastplate of nestlings Gigant Amazoniam turtle (P.expansa) fed diets with different crude protein levels. 
Tabela 2 - Características de crescimento corporal em filhotes de tartarugas gigantes da Amazônia (P.expansa) alimentados com dietas com diferentes níveis e tipo de proteína até os dez meses de idade

Table 2 - Body growth characteristics in nestlings of giant Amazonian turtle (P.expansa) fed diets with different levels and protein type to the ten months of age

\begin{tabular}{|c|c|c|c|c|c|c|c|c|c|c|c|c|c|c|c|c|}
\hline \multirow[b]{2}{*}{ Idade } & \multirow[b]{2}{*}{ Grupo } & \multirow[b]{2}{*}{ PB } & \multicolumn{3}{|c|}{$\begin{array}{l}\text { Comp. carapaça } \\
\text { Length shell }\end{array}$} & \multicolumn{3}{|c|}{$\begin{array}{c}\text { Larg. carapaça } \\
\text { Width shell }\end{array}$} & \multicolumn{3}{|c|}{$\begin{array}{l}\text { Comp. plastrão } \\
\text { Length breastplate }\end{array}$} & \multicolumn{3}{|c|}{$\begin{array}{l}\text { Larg. plastrão } \\
\text { Width breastplate }\end{array}$} & \multicolumn{2}{|c|}{$\begin{array}{c}\text { Peso corporal } \\
\text { Body weight }\end{array}$} \\
\hline & & & $X$ & & $\mathrm{DP} \mathrm{cm}$ & X & & $\mathrm{DP} \mathrm{cm}$ & $\mathrm{X}$ & & $\mathrm{DP} \mathrm{cm}$ & $X$ & & $\mathrm{DP} \mathrm{cm}$ & $X$ & DP kg \\
\hline \multirow[t]{6}{*}{30} & PBA30 & $30 \%$ & 53,5 & \pm & $0,6 a$ & 49,5 & \pm & $0,5 a$ & 36,6 & \pm & $0,3 a$ & 46,5 & \pm & $0,5 a$ & 27,1 & $\pm 1,5 \mathrm{a}$ \\
\hline & PB18 & $18 \%$ & 53,1 & \pm & $0,6 a$ & 49,6 & \pm & $0,5 a$ & 36,8 & \pm & $0,3 a$ & 46,5 & \pm & $0,5 a$ & 27,2 & $\pm 1,5 \mathrm{a}$ \\
\hline & PB21 & $21 \%$ & 53,1 & \pm & $0,6 a$ & 49,4 & \pm & $0,5 a$ & 36,6 & \pm & $0,3 a$ & 46,3 & \pm & $0,5 a$ & 26,9 & $\pm 1,5 a$ \\
\hline & PB24 & $24 \%$ & 53,4 & \pm & $0,6 a$ & 49,6 & \pm & $0,5 \mathrm{a}$ & 36,8 & \pm & $0,3 a$ & 46,6 & \pm & $0,5 a$ & 27,1 & $\pm 1,5 a$ \\
\hline & PB27 & $27 \%$ & 53,5 & \pm & $0,6 a$ & 49,6 & \pm & $0,5 a$ & 36,8 & \pm & $0,3 a$ & 46,6 & \pm & $0,5 a$ & 27,3 & $\pm 1,5 a$ \\
\hline & PB30 & $30 \%$ & 53,4 & \pm & $0,6 a$ & 49,4 & \pm & $0,5 a$ & 36,8 & \pm & $0,3 a$ & 46,5 & \pm & $0,5 a$ & 27,1 & $\pm 1,5 a$ \\
\hline \multirow[t]{6}{*}{90} & PBA30 & $30 \%$ & 57,7 & \pm & $0,7 a$ & 52,3 & \pm & $0,5 a$ & 38,0 & \pm & $0,4 a$ & 49,0 & \pm & $0,6 a$ & 31,9 & $\pm 1,8 a$ \\
\hline & PB18 & $18 \%$ & 57,6 & \pm & $0,6 a$ & 52,5 & \pm & $0,5 \mathrm{a}$ & 38,2 & \pm & $0,4 a$ & 48,9 & \pm & $0,5 a$ & 32,9 & $\pm 1,7 \mathrm{a}$ \\
\hline & PB21 & $21 \%$ & 58,0 & \pm & $0,6 a$ & 52,8 & \pm & $0,5 a$ & 38,0 & \pm & $0,3 a$ & 49,0 & \pm & $0,5 a$ & 33,3 & $\pm 1,6 a$ \\
\hline & PB24 & $24 \%$ & 58,6 & \pm & $0,6 a$ & 53,2 & \pm & $0,5 \mathrm{a}$ & 38,4 & \pm & $0,3 a$ & 49,5 & \pm & $0,5 a$ & 34,8 & $\pm 1,5 \mathrm{a}$ \\
\hline & PB27 & $27 \%$ & 59,6 & \pm & $0,6 a$ & 53,8 & \pm & $0,5 \mathrm{a}$ & 38,8 & \pm & $0,3 a$ & 50,0 & \pm & $0,5 a$ & 36,1 & $\pm 1,6 a$ \\
\hline & PB30 & $30 \%$ & 59,4 & \pm & $0,6 a$ & 53,9 & \pm & $0,5 a$ & 38,7 & \pm & $0,3 a$ & 49,8 & \pm & $0,5 a$ & 36,7 & $\pm 1,7 \mathrm{a}$ \\
\hline \multirow[t]{6}{*}{150} & PBA30 & $30 \%$ & 68,3 & \pm & $0,7 a$ & 60,1 & \pm & $0,5 a$ & 43,1 & \pm & $0,4 a$ & 55,9 & \pm & $0,5 a$ & 52,6 & $\pm 1,8 \mathrm{a}$ \\
\hline & PB18 & $18 \%$ & 64,1 & \pm & $0,6 a$ & 57,6 & \pm & $0,5 a$ & 41,6 & \pm & $0,4 a$ & 53,6 & \pm & $0,5 \mathrm{a}$ & 44,9 & $\pm 1,7 \mathrm{a}$ \\
\hline & PB21 & $21 \%$ & 65,6 & \pm & $0,6 a$ & 58,8 & \pm & $0,5 a$ & 42,1 & \pm & 0,3a & 54,4 & \pm & $0,5 a$ & 47,5 & $\pm 1,6 a$ \\
\hline & PB24 & $24 \%$ & 65,7 & \pm & $0,6 a$ & 58,6 & \pm & $0,5 \mathrm{a}$ & 42,2 & \pm & $0,3 a$ & 54,6 & \pm & $0,5 \mathrm{a}$ & 48,4 & $\pm 1,5 \mathrm{a}$ \\
\hline & PB27 & $27 \%$ & 66,8 & \pm & $0,6 a$ & 59,0 & \pm & $0,5 a$ & 42,3 & \pm & $0,3 a$ & 55,4 & \pm & $0,5 a$ & 49,2 & $\pm 1,6 a$ \\
\hline & PB30 & $30 \%$ & 67,2 & \pm & $0,6 a$ & 60,0 & \pm & $0,5 a$ & 43,1 & \pm & $0,3 a$ & 55,9 & \pm & $0,5 a$ & 51,7 & $\pm 1,7 \mathrm{a}$ \\
\hline \multirow[t]{6}{*}{210} & PBA30 & $30 \%$ & 76,4 & \pm & $0,7 a$ & 66,5 & \pm & $0,5 \mathrm{a}$ & 47,2 & \pm & $0,4 a$ & 63,1 & \pm & $0,6 a$ & 73,1 & $\pm 1,8 \mathrm{a}$ \\
\hline & PB18 & $18 \%$ & 69,0 & \pm & $0,7 c$ & 61,5 & \pm & $0,5 c$ & 43,8 & \pm & $0,4 \mathrm{c}$ & 56,9 & \pm & $0,5 c$ & 55,3 & $\pm 1,8 \mathrm{c}$ \\
\hline & PB21 & $21 \%$ & 70,1 & \pm & $0,6 c$ & 62,2 & \pm & $0,5 b c$ & 44,2 & \pm & $0,3 \mathrm{bc}$ & 57,7 & \pm & $0,5 c$ & 56,9 & $\pm 1,6 c$ \\
\hline & PB24 & $24 \%$ & 71,8 & \pm & $0,6 \mathrm{bc}$ & 63,5 & \pm & $0,5 b c$ & 44,7 & \pm & $0,3 b$ & 59,4 & \pm & $0,5 b c$ & 62,0 & $\pm 1,5 \mathrm{bc}$ \\
\hline & PB27 & $27 \%$ & 73,4 & \pm & $0,6 a b$ & 64,0 & \pm & $0,5 \mathrm{ab}$ & 45,6 & \pm & $0,3 a b$ & 60,8 & \pm & $0,5 a b$ & 65,8 & $\pm 1,6 \mathrm{ab}$ \\
\hline & PB30 & $30 \%$ & 73,9 & \pm & 0,6ab & 64,6 & \pm & $0,5 a b$ & 46,1 & \pm & 0,3ab & 60,7 & \pm & $0,5 a b$ & 67,5 & $\pm 1,7 \mathrm{ab}$ \\
\hline \multirow[t]{6}{*}{270} & РBA30 & $30 \%$ & 81,9 & \pm & $0,7 a$ & 70,7 & \pm & $0,5 a$ & 50,1 & \pm & $0,4 a$ & 67,6 & \pm & $0,6 a$ & 86,0 & $\pm 1,8 \mathrm{a}$ \\
\hline & PB18 & $18 \%$ & 73,0 & \pm & $0,6 c$ & 64,5 & \pm & $0,5 \mathrm{~d}$ & 45,8 & \pm & $0,4 d$ & 60,2 & \pm & $0,5 c$ & 63,4 & $\pm 1,8 \mathrm{c}$ \\
\hline & PB21 & $21 \%$ & 74,6 & \pm & $0,6 c$ & 65,9 & \pm & $0,5 \mathrm{~cd}$ & 46,2 & \pm & $0,3 \mathrm{~d}$ & 61,1 & \pm & $0,5 c$ & 66,2 & $\pm 1,6 c$ \\
\hline & PB24 & $24 \%$ & 77,9 & \pm & $0,6 b$ & 68,0 & \pm & $0,5 b c$ & 48,0 & \pm & $0,3 \mathrm{bc}$ & 64,1 & \pm & $0,5 b$ & 76,1 & $\pm 1,5 b$ \\
\hline & PB27 & $27 \%$ & 79,5 & \pm & $0,6 a b$ & 68,8 & \pm & $0,5 \mathrm{ab}$ & 48,7 & \pm & $0,3 a b$ & 65,9 & \pm & $0,5 a b$ & 80,3 & $\pm 1,6 \mathrm{ab}$ \\
\hline & PB30 & $30 \%$ & 78,3 & \pm & $0,6 b$ & 68,4 & \pm & $0,5 \mathrm{ab}$ & 48,4 & \pm & $0,3 b$ & 64,5 & \pm & $0,5 a b$ & 78,2 & $\pm 1,7 \mathrm{~b}$ \\
\hline \multirow[t]{6}{*}{330} & PBA30 & $30 \%$ & 103,7 & \pm & $0,7 a$ & 87,4 & \pm & $0,5 a$ & 61,7 & \pm & $0,4 a$ & 86,8 & \pm & $0,6 \mathrm{a}$ & 158,4 & $\pm 1,8 \mathrm{a}$ \\
\hline & PB18 & $18 \%$ & 91,1 & \pm & $0,6 c$ & 77,4 & \pm & $0,5 c$ & 55,3 & \pm & $0,4 c$ & 75,4 & \pm & $0,5 c$ & 110,7 & $\pm 1,8 \mathrm{~cd}$ \\
\hline & PB21 & $21 \%$ & 87,7 & \pm & $0,6 \mathrm{~d}$ & 75,2 & \pm & $0,5 c$ & 53,2 & \pm & $0,3 d$ & 72,6 & \pm & $0,5 d$ & 102,9 & $\pm 1,6 \mathrm{~d}$ \\
\hline & PB24 & $24 \%$ & 90,4 & \pm & $0,6 \mathrm{~cd}$ & 76,0 & \pm & $0,5 c$ & 54,3 & \pm & $0,3 \mathrm{~cd}$ & 74,3 & \pm & $0,5 \mathrm{~cd}$ & 111,6 & $\pm 1,5 c$ \\
\hline & PB27 & $27 \%$ & 95,1 & \pm & $0,6 b$ & 80,0 & \pm & $0,5 \mathrm{bc}$ & 57,6 & \pm & $0,3 b$ & 80,5 & \pm & $0,5 b$ & 129,2 & $\pm 1,6 b$ \\
\hline & PB30 & $30 \%$ & 96,5 & \pm & $0,6 b$ & 81,6 & \pm & $0,5 b$ & 57,8 & \pm & $0,3 b$ & 80,1 & \pm & $0,5 b$ & 129,1 & $\pm 1,7 \mathrm{~b}$ \\
\hline
\end{tabular}

Comp. = Comprimento; Larg. $=$ Largura.

Letras iguais entre grupos indica que não existe diferença significativa entre os tratamentos; $\mathrm{P}<0,001$.

PB27 e os grupos PB18 e PB21 como os de menores resultados de crescimento. O grupo PB24 oscilou entre os grupos intermediários e inferiores, dependendo da característica analisada.

As tartarugas, em geral, possuem taxas de crescimento distintas ao longo da vida. No primeiro ano de vida, até a fase juvenil, a taxa de crescimento é maior em relação aos adultos (Bataus, 1998). De modo geral, as fêmeas de quelônios possuem taxa de crescimento absoluto maior que as dos machos e seu valor pode estar associado às estratégias reprodutivas, às condições ambientais e aos fatores genéticos (Legler, 1960; Onorarato, 1998, citado por Bataus, 1996).

\footnotetext{
R. Bras. Zootec., v.33, n.6, p.2351-2358, 2004 (Supl. 3)
} 
Segundo Andrews (1982), o crescimento do corpo dos répteis é uma função não-linear do tempo influenciada pelas condições ambientais externas e por fatores biológicos, como sexo e maturidade sexual. No presente experimento, foram desprezados os efeitos de sexo e a proporção de machos e de fêmeas, em razão da falta de recursos que possibilitassem a separação proporcional de animais por sexo em cada grupo, podendo a maior proporção de um ou outro sexo causar diferença significativa, uma vez que, no dimorfismo sexual da espécie, as fêmeas adultas são 1,3 vezes maiores que os machos (Bataus,1998). Na espécie Pseudemis scripta, em condições ambientais ideais de crescimento, os machos alcançam a maturidade na mesma idade que as fêmeas, que atingem a maturidade com tamanho maior (Gibbons, 1967). Por esta razão, há possibilidade de um viés embutido, pois a ausência e a não-diferença significativa entre os grupos que receberam rações com valores intermediários, em quase todos os parâmetros medidos, evidenciaram que a diferença de3\% na quantidade de proteína bruta não é suficiente para determinar crescimento diferenciado ou que a qualidade da proteína fornecida ao grupo PBA30 foi realmente superior. A separação de animais por sexo, neste experimento, não ocorreu, devido à ausência de dimorfismo sexual evidente na fase neo-natal, associado à impossível diferenciação genética, pois, segundo Ewert et al. (1994), a espécie em estudo expressa temperatura-sexo-dependente.

O incremento percentual de todas as variáveis medidas parece obedecer à variação climática, de modo que no período do ano em que ocorrem as temperaturas mais baixas existe o menor aproveitamento da ração, sugerindo a necessidade de manejo diferenciado para se evitarem perdas econômicas (Figura 5).

Observaram-se dois aumentos do percentual médio do peso corporal durante o experimento, que coincidiram com épocas (janeiro-março e agostosetembro) de temperaturas mais elevadas na região (Figura 5). Na primeira fase, destacou-se o maior percentual do peso corporal no grupo de tratamento com proteína animal PBA30, não havendo diferença entre os demais. No segundo período, apareceram as diferenças, como constatado na comparação de médias das medidas de crescimento corporal, em que a proteína animal proporcionou ganhos de peso corporal de modo que o grupo PBA30 foi acompanhado pelos tratamentos com proteína vegetal.

\footnotetext{
R. Bras. Zootec., v.33, n.6, p.2351-2358, 2004 (Supl. 3)
}
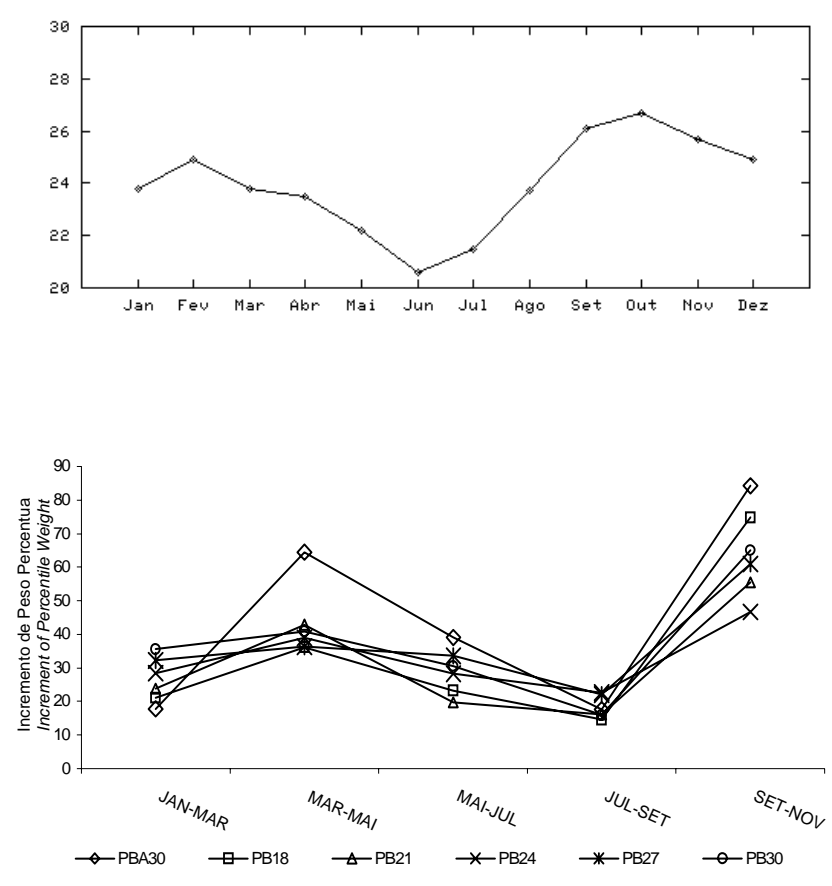

Figura 5 - Temperatura média $\left(\mathrm{C}^{\circ}\right)$ em Goiânia no período de 1997 (Instituto Nacional de Meteorologia). Efeito da temperatura sobre o incremento percentual médio do peso corporal.

Figure 5 - Average temperature $\left(C^{\circ}\right)$ in Goiânia in the period of 1997 (National Institute of Meteorology). Effect of the temperature on the medium percentile increment of the corporal weight.

Esta observação poderia servir para estabelecer estratégias de minimizar os custos com ração na engorda desta espécie, podendo o teor e o tipo de proteína serem fornecidos em estações em que fossem melhor aproveitados.

Elevação da temperatura acarreta aumento no consumo de alimento, no metabolismo da digestão (Parmenter, 1981) e na eficiência digestiva, não só em tartaruga, mas também em outros répteis (Zimmerman, 1989). Avery et al. (1993) observaram que dietas com alto nível de proteína bruta, aliadas a temperaturas elevadas, proporcionaram os melhores resultados quanto ao crescimento.

Vianna \& Abe (1998) sugerem que, nos períodos mais frios do ano, podem-se adotar menores níveis de proteína como medida econômica na produção de tracajás, porém não houve evidência estatística e, portanto, o dimorfismo sexual da espécie foi desconsiderado.

Em função das possíveis diferenças de nicho e alimentar, sugere-se a separação de grupos de animais 
por tamanho, com níveis mais elevados de proteína para animais maiores e níveis mais baixos para animais menores, mas nunca inferiores a $27 \% \mathrm{~PB}$, como constatado neste trabalho, pois a diferença média de ganho de peso sofreu decréscimo de 3 a $15 \%$ do peso total.

\section{Conclusões}

Filhotes de $P$. expansa nos dez primeiros meses de vida alimentados com dietas com elevados percentuais de proteína bruta totalmente de origem vegetal acima de $27 \%$ respondem melhor em termos de crescimento e de ganho de peso que quando alimentados com dietas com percentuais mais baixos. A dieta contendo proteína bruta de origem animal apresentou melhores resultados que as de origem vegetal. Ainda há a necessidade de estudos adicionais, uma vez que a nutrição e produção de répteis são um assunto singular quando comparado à nutrição e produção de animais já domesticados.

\section{Agradecimento}

Prof. Milton Moreira Lima, pela colaboração no Laboratório de Análises Bromatológicas da UFG; Eng.Florestal Vitor Hugo Cantarelli CENAQUA/ IBAMA; Kelly Bonach e Lívia Bonach, acadêmicas de Medicina Veterinária.

\section{Literatura Citada}

AVERY, H.W.; SPOTILA, J.R.; CONGDON, J.D. et al. Role of diet protein and temperature in the growth and nutritional energetics of juvenile slider turtles, Trachemys scripta. Physiological Zoology, v.66, n.6, p.902-925, 1993.

ALHO,C.J.R.; PÁDUA, L.F.M. Sincronia entre o regime de vazante do rio e o comportamento de nidificação da Tartaruga da Amazônia, Podocnemis expansa, (Testudinata: Pelomedusidae). Acta Amazônica, v.12, n.2, p.323-326, 1982.
ANDREWS,R.M. Patterns growth in reptiles. In: GANS, C.; POUGH, F.H. (Eds.). Biology of the reptilia. London: Academic Press, 1982. p.273-320.

BATAUS, Y.S.L Estimativa de parâmetros populacionais de Podocnemis Expansa (tartaruga-da-Amazônia) no rio Crixás-Açu (GO) a partir de dados biométricos. Goiânia: Universidade Federal de Goiás, 1998. 54p. Dissertação (Mestrado) - Universidade Federal de Goiás, 1998.

EWERT, M.A., JACKSON. D.; NELSON, C. Patterns of temperature-dependent sex determination in turtles. Journal of Experimental Zoology, v.270, p.3-15, 1994.

GIBBONS J.W. Variation in growth rates in three population of the paint turtle Chrysemy picta. Herpentologica, v. 23, n.4, p.296-302, 1967.

INSTITUTO NACIONAL DE METEOROLOGIA (INMET) MINISTERIO DE AGRICULTURA, PECUARIA E ABASTECIMENTO. http://www.inmet.gov.br/ climatologia/ combo_climatologia_I.html. Ultimo acesso em 12/06/2002.

LEGLER, J.M. Distributional records of amphibians and reptiles in Kansas. Transaction Kans. Academy Science, v.63, p.40-53, 1960.

MARTins, G.B.; DONAIRE, D. Princípios de estatística. 4.ed. São Paulo: Atlas, 1985. 255p.

OJASTI, J. Consideraciones sobre la ecología y conservación de la tortuga "Podocnemis expansa" (Chelonia, Pelomedusidae). In: SIMPÓSIO SOBRE A BIOTA AMAZÔNICA (CONSERVAÇÃO DA NATURALEZA E RECURSOS NATURAIS), 1967. ATAS... 1967. p.201-206.

PARMENTER, R.R. Digestive turnover rates in freswater turtles: the influence of temperature and body size. Compedium Biochemistry Physiology, v.70, p.235-238, 1981.

SILVA, J.D. Análise de alimentos (métodos químicos e biológicos). 2.ed. Viçosa, MG. Universidade Federal de Viçosa, 1990. 165p.

STATISTICAL ANALYSES SYSTEM - SAS. SAS user's guide: statistics. 6.ed. Cary: 1997. 670p.

VIANNA, V.O; ABE, A.S. Efeito de diferentes níveis de proteína no desenvolvimento de filhotes de tracajá (Podocnemis unifilis) em cativeiro. In: REUNIAO ANUAL DA SOCIEDADE BRASILEIRA DE ZOOTECNIA, 35., 1998, Botucatu. Anais... São Paulo Gnosis, 1998, CD-ROM, Pequenos Animais e Animais Silvestre, Tra. 28.

ZIMMERMAN, L.C.; TRACY, C.R. Interactions between the environment and ectothermy and herbivory in reptiles. Physiological Zoology, v.62, p.374-409, 1989.

Recebido em: 22/04/03 Aceito em: 02/04/04 